\title{
O SISTEMA AGRÁRIO DE TRÁS-OS-MONTES E A MODERNIDADE SUSTENTÁVEL*
}

\section{Manuel Colaço do Rosário**}

Depois de situar o agros no contexto rural, faz-se um esboço de ordenamento do território da Região Agrária de Trás-os-Montes segundo o critério ecológico-agrário e define-se a abordagem ao estudo, com destaque para a perspectiva agrária tradicional.

Segue-se um exaustivo mas sintético reconhecimento do território transmontano em termos dos meios agro-natural (recursos agro-naturais) e agrário humanizado (estruturas agrárias), no âmbito da integração agrária.

Finalmente, aborda-se a modernização do sistema agrário transmontano em termos da multifuncionalidade sustentável.

Palavras Chave: contexto rural, agro-natural, modernização, agrária

After having placed the agros (agrarian sector) within the rural context, it was made an outline of Trás-os-Montes Agrarian Region's land management based on ecological-agrarian criterion. It is also defined the study approach, emphasizing the traditional agrarian perspective.

It follows an exhaustive, but summarised, recognition of the territory in Trás-os-Montes region as regards agro-natural resources and agrarian structures, within the framework of agrarian integration.

Finally, it is approached the modernization of the agrarian system in Trás-os-Montes region concerning its sustainable multifunctionality.

Key words: rural context, agro-natural, modernization, agrarian

** Universidade de Trás-os-Montes e Alto Douro - Departamento de Economia e Sociologia. 


\section{1 - INTRODUÇÃO}

A perspectiva da orientação agrária sustentada baseia-se no conceito de modernidade no equilíbrio ${ }^{1}$ e assenta na abordagem integrada do agros $^{2}$. Esta encara os eco-sistemas agro-natural e agrário humanizado como suporte do estabelecimento das medidas de orientação agrária que, nos espaços ${ }^{3}$ ecológica e estruturalmente afins, tendem a gerar agro-sistemas idênticos, embora dependentes da natureza e intensidade da intervenção humana. $\mathrm{O}$ estudo contempla a Região Agrária $\mathrm{Natural}^{4}$ de Trás-os-Montes e as respectivas Zonas Agrárias Homogéneas ${ }^{5}$, que o esboço de ordenamento do território comporta, representativas das várias sensibilidades do domínio ecológico sub-atlante-continental e mediterrânico, definidas segundo o critério ecológico-agrário (Pereira, 1993), representando duas escalas do mesmo critério.

O território do Norte de Portugal, segundo o critério ecológico, compreende quatro regiões agro-naturais: Região Agrária do Grande-Porto, Região Agrária do Minho, Região Agrária de Trás-os-Montes e Região Agrária do Douro. A Região Agrária de Trás-os-Montes integra as Zonas Agrárias Homogéneas do Alto Tâmega-Barroso, do Marão-Padrela, da Terra Fria, do Planalto Mirandês e a heterogénea da Terra Quente (atípica, relativamente à respectiva matriz ecológico-agrária).

$\mathrm{Na}$ delimitação das novas unidades agro-geográficas de base ecológica, foi utilizado o método da sobreposição (overlay) sobre as Cartas Hipsométrica (1982), Ecológica (1984) e das Regiões Naturais (1985), associado à utilização do planímetro para a medição das respectivas áreas, através das quais se procedeu à avaliação da proporção percentual das representações dos vários atributos. 
Quadro $n^{\circ} 1$

COMPOSIÇÃO MUNICIPAL DAS ZONAS AGRÁRIAS HOMOGÉNEAS DA REGIÃO AGRÁRIA NATURAL DE TRÁS-OS-MONTES SEGUNDO O ESBOÇO DE ORDENAMENTO ESPACIAL ECOLÓGICO-AGRÁRIO

\begin{tabular}{|c|c|c|c|c|c|}
\hline \multicolumn{6}{|c|}{ Região Agrária Natural de Trás-os-Montes } \\
\hline \multicolumn{3}{|c|}{ Zona Agrária do Alto Tâmega-Barroso } & \multicolumn{3}{|c|}{ Zona Agrária do Marão-Padrela } \\
\hline Municípios & $\mathrm{Km}^{2}$ & $\%$ & Municípios & $\mathrm{Km}^{2}$ & $\%$ \\
\hline Chaves & 597,50 & 100 & Vila Pouca de Aguiar & 413,31 & 96 \\
\hline Boticas & 310,00 & 96 & Vila Real & 266,42 & 70 \\
\hline Montalegre & 601,80 & 75 & Mondim de Basto & 93,74 & 55 \\
\hline Vieira do Minho & 120,00 & 55 & Ribeira de Pena & 118,75 & 54 \\
\hline Valpaços & 268,95 & 49 & Baião & 93,21 & 53 \\
\hline Cabeceiras de Basto & 106,88 & 44 & Murça & 96,26 & 51 \\
\hline Ribeira de Pena & 19,38 & 9 & Alijó & 125,70 & 42 \\
\hline \multirow[t]{7}{*}{ Vila Pouca de Aguiar } & 19,38 & 4 & Amarante & 83,31 & 28 \\
\hline & & & Carrazeda de Ansiães & 73,50 & 26 \\
\hline & & & Sabrosa & 38,33 & 24 \\
\hline & & & Valpaços & 91,88 & 16 \\
\hline & & & $\mathrm{St}^{\mathrm{a}}$ Marta de Penaguião & 7,48 & 11 \\
\hline & & & Régua & 9,38 & 10 \\
\hline & & & Mesão Frio & 0,60 & 2 \\
\hline \multicolumn{3}{|c|}{ Zona Agrária da Terra Fria } & \multicolumn{3}{|c|}{ Zona Agrária do Planalto Mirandês } \\
\hline Municípios & $\mathrm{Km}^{2}$ & $\%$ & Municípios & $\mathrm{Km}^{2}$ & $\%$ \\
\hline Bragança & 1153,93 & 98 & Miranda do Douro & 488,36 & 100 \\
\hline Vinhais & 659,95 & 95 & Mogadouro & 720,08 & 95 \\
\hline Macedo de Cavaleiros & 559,42 & 80 & Vimioso & 457,40 & 95 \\
\hline Alfandega da Fé & 32,20 & 10 & Torre de Moncorvo & 143,85 & 27 \\
\hline Mirandela & 8,50 & 1,2 & Freixo de Espada-à-Cinta & 21,39 & 9 \\
\hline
\end{tabular}

Zona Agrária da Terra Quente

\begin{tabular}{l|c|c|l|c|c}
\hline \multicolumn{1}{c|}{ Municípios } & $\mathrm{Km}^{2}$ & $\%$ & \multicolumn{1}{|c|}{ Municípios } & $\mathrm{Km}^{2}$ & $\%$ \\
\hline Mirandela & 616,20 & 94 & Torre de Moncorvo & 45,00 & 8 \\
Alfandega da Fé & 273,67 & 85 & Mogadouro & 37,90 & 5 \\
Vila Flôr & 146,04 & 55 & Vinhais & 34,73 & 5 \\
Valpaços & 192,24 & 35 & Vimioso & 24,07 & 5 \\
Macedo de Cavaleiros & 139,85 & 20 & Carrazeda de Ansiães & 11,24 & 4 \\
Murça & 26,85 & 14 & Bragança & 20,00 & 2 \\
\hline
\end{tabular}

Fonte: Adaptado de Rosário (1998)

A delimitação das Zonas Agrárias Homogéneas, segundo o critério ecológico-agrário, fraccionou as unidades administrativas Municípios e 
Freguesias, pelo que obrigou à avaliação das áreas geográficas repartidas pelas zonas limítrofes. Assim, com base no factor geográfico ${ }^{6}$ (proporção percentual das áreas distribuídas pelas zonas limítrofes), os atributos foram repartidos de acordo com a proporção de área que coube a cada zona, que consistiu em multiplicar o valor do atributo pelo factor geográfico de correcção. Contudo, para a maior parte dos atributos, a ocorrência não é homogénea pela unidade administrativa, antes acompanha as diferentes ecologias em que assentou a delimitação das Zonas Homogéneas, daí que se tivesse considerado um factor ecológico de correcção ${ }^{7}$, que consistiu em multiplicar a fracção da área da unidade administrativa mais favorável ao atributo por um coeficiente entre 1,5 e 3, conforme o grau de especialização para o mesmo, enquanto a área da outra fracção foi dividida por idêntico valor, isto depois da correcção geográfica.

Quanto à metodologia seguida para a caracterização do meio agro-natural, utilizou-se a pesquisa cartográfica, enquanto para o meio agrário humanizado se recorreu à pesquisa bibliográfica, com excepção para a agro-flora cultivada.

A Região Agrária de Trás-os-Montes tem como matriz de ordenamento diferenciadora das zonas agrárias homogéneas, sobretudo, os sistemas montanhosos com suas serras, planaltos e vales sub-montanos, à excepção da atípica Zona Agrária da Terra Quente, baseada na bacia do vale do Tua e peneplanícies envolventes. Esta divisão sobrepôs o critério ecológico ao administrativo seguido pelos Serviços Oficiais Agrários, por se entender que o limite dos Municípios como base de demarcação das Zonas Agrárias não respeita o objectivo de homogeneidade subjacente ao ordenamento territorial agrário, passível de um tratamento mais específico.

Tendo em conta que as orientações agrárias mais adequadas têm de assentar no profundo conhecimento das múltiplas componentes do agros - ambiental física, biológica e socioeconómica, procedeu-se ao reconhecimento exaustivo, embora sintético, dos meios agro-natural e agrário humanizado. Esta abordagem integrada do agros visa recuperar a perspectiva tradicional com que o mesmo era encarado, quando a integração agrária era um facto, e ao agrário cabia, naturalmente, o arranjo das paisagens agrárias, missão que ao nível da União Europeia, após as reformas da Política Agrária Comum (PAC) de 1992 e 2000, se voltam a reconhecer como conservadoras dos recursos agro-naturais - as medidas agro-ambientais.

O agrário tradicional desempenhava o conjunto de actividades que vão do processo produtivo à transformação e distribuição da maior parte dos produtos, apropriando os respectivos valores acrescentados, fossem eles bens, serviços ou numerário, na perspectiva do que na era moderna 
convencional se designa por fileira. Contudo, em muitos casos, esta integração verifica-se apenas enquanto sistema de organização económica visando racionalizar as actividades, independentemente da natureza dos agentes socioeconómicos que beneficiam da repartição dos respectivos valores acrescentados. Aqui surge a distinção da concepção agrarista, que se perfilha, a qual integra também a dimensão agro-natural e defende a apropriação pelas classes agrárias respectivas das mais-valias geradas pela integração agrária como única forma de garantir aos agrários rendimentos equivalentes aos das outras classes profissionais e, simultaneamente, de assegurar uma situação estável e multiplamente positiva para a relação homem - terra, ao serviço da protecção dos recursos agro-naturais, do abastecimento agro-alimentar, agro-complementar e agro-recreativo. Mas tal exige conhecimentos e competências para gerir todo o complexo agrário. No entanto, esclarece-se que a concepção agrarista não é sinónima de fisiocrata, pois não trata de hierarquizar a importância dos sectores económicos, antes de assumir o sector agrário na linha da modernidade no equilíbrio (Rosário, 1998).

O agrário tradicional dispunha de recursos escassos cuja utilização procurava gerir da melhor forma para garantir o abastecimento e a sobrevivência do seu agregado familiar. Por isso, o retomar da lógica e da racionalidade subjacentes às práticas do agrário tradicional constitui um elemento central do quadro de referência da análise e da interpretação do agros seguida neste estudo, na dualidade das vertentes que o integram, ou seja, o meio agro-natural e o meio agrário humanizado.

\section{2 - O MEIO AGRO-NATURAL TRANSMONTANO}

Este compreende os recursos agro-naturais com suas componentes agro-climática, agro-fisiográfica, agrológica, agro-hídrica, agro-florística e agro-faunística.

\section{1 - Recursos Agro-Climáticos}

O agrário tradicional estudava o tempo (recursos agro-climáticos), porque lhe reconhecia o carácter de factor limitante das actividades e práticas agrárias, a cujos ciclos se ajustava sabiamente.

O clima é sub-atlântico/continental e mediterrânico, representado por Terra Fria de Planalto, Terra Fria de Montanha, Terra Fria de Alta Montanha, Terras de Transição e Terra Quente (zona atípica), influenciado pela atlanticidade húmida de oeste, continentalidade fria $\mathrm{e}$ seca de leste e quente de sul (Carta do Nordeste de Portugal, 1991). A zonagem ecológica de Trás-os-Montes destaca os domínios: Atlântico 
(50\%), Ibérico (26\%) e Mediterrânico (24\%) e quatro agrotipos Montanha de Granito e Xisto (níveis pastoril e florestal), Meia Encosta Nordestina, Terra Fria Transmontana e Terra Quente Transmontana (zona atípica). Tem como indicadores fitoclimáticos o carvalho negral, o castanheiro, a azinheira e o sobreiro (Albuquerque, 1984 e 1985).

\section{2 - Recursos Agro-Fisiográficos}

O agrário tradicional estudava o terreno (recursos agro-fisiográficos), traduzido nas suas componentes altitude, relevo, declive, exposição e cursos de água, procurando adaptar-se a cada uma delas no sentido de melhor aproveitar as suas aptidões e nelas intervindo para melhorar as suas capacidades produtivas.

A fisiografia é dominada pela hipsometria montana e sub-montana, dos 450-600m (limite natural da cultura da vinha) aos 1500m (Comissão Nacional do Ambiente, 1982). O relevo regista uma representação de pene-planalto e serra cortados por vales sub-montanos de encostas abruptas. A exposição é variada, embora dominante de oeste e este, uma vez que a orientação dominante dos sistemas montanhosos é norte-sul. $\mathrm{O}$ declive destaca os escalões $\mathrm{C}_{1}-3, \mathrm{C}_{4}$ e $\mathrm{C}_{5}$, correspondendo o primeiro aos planaltos (Carta dos Declives da Comissão Nacional do Ambiente, 1987). Quanto aos cursos de água dominantes, destacam-se os ribeiros e rios de pequeno e médio porte, de curso nacional exclusivo (rios Corgo, Pinhão, Tua e Sabor) e luso-espanhol (rios Tâmega, Douro e Tuela e Rabaçal, afluentes do Tua).

\section{3 - Recursos Agrológicos}

O agrário tradicional estudava as terras (recursos agrológicos) como um bem renovável, por si próprio e pela Natureza, respeitando-lhes as capacidades e devolvendo à terra, ano a ano, os nutrientes gastos com a cultura. Este processo de reposição e enriquecimento do respectivo fundo de fertilidade traduzia a perspectiva edificante de quem via na terra $o$ recurso produtivo eterno que, em conjunto com a água, havia de garantir a sua subsistência e das futuras gerações.

Os solos dominantes são de origem granítica e afins, associados aos xistos e grauvaques. Com base na Carta de Solos de Portugal (Cardoso et al., 1978), a caracterização lito-pedológica destaca Bh1,2 (rochas eruptivas) e Ie2,3,7 (xistos e grauvaques, básicos e ultra-básicos). Quanto à aptidão da terra, dominam as unidades Cambissolos húmicos $\mathrm{e}$ Leptossolos êutricos (Carta de Solos do Nordeste de Portugal, 1991). Segundo a Carta de Capacidade de Uso do Solo, $\operatorname{SROA}^{8}$ (1982), regista- 
-se o domínio dos atributos Uso Florestal, Agrícola Condicionado e Florestal (pascícola), e Agrícola.

\section{4 - Recursos Agro-Hídricos}

O agrário tradicional estudava as águas (recursos agro-hídricos) como um bem renovável pela Natureza, cuja disponibilidade podia ser prolongada pelas Estações mais secas, objectivo a que se aplicava no sentido do aumento das produções de Primavera-Verão e do abastecimento doméstico e animal.

A hidrografia é representada por bacias hidrográficas múltiplas, de altitude e rede hidrográfica com densidade e frequência média. As bacias hidrográficas compreendem superfície portuguesa e luso-espanhola, na ordem dos 75 e $25 \%$, respectivamente. A participação da área espanhola corresponde à bacia dos rios Tâmega, do Tuela e Rabaçal (afluentes do Tua), Maçãs (afluente do Sabor) e Douro (Divisão do Atlas do Ambiente, 1989). O escoamento das bacias hidrográficas é dominado pelo escalão $400-600 \mathrm{~mm}$ e do $200-400 \mathrm{~mm}$, que correspondem aos andares hipsométricos montano e sub-montano (Quintela, 1975).

\section{5 - Recursos Agro-Florísticos Silvestres}

$\mathrm{O}$ agrário tradicional encarava as plantas espontâneas e subespontâneas (recursos agro-florísticos silvestres) com o objectivo múltiplo de lhe conhecer os comportamentos e as utilizações, desde alimentares humanas e animais, medicinais e complementares, às de função de indicador eco-fitológico, constituindo o principal guia do camponês no ordenamento das culturas.

A flora silvestre é do tipo sub-atlante-continental-mediterrânica, com destaque para o carvalho-negral, o carvalho-roble, o carvalho-cerquinho, o castanheiro, o pinheiro-bravo, a azinheira e o sobreiro, entre as arbóreas, com utilizações em marcenaria, tanoaria, carpintaria, artigos de cortiça, alimento animal, pasta de celulose, postes, resina, carvão e lenhas, curtimenta de peles, melífera, medicinal e ornamental paisagística. As arbustivas salientam o domínio das giestas (piorneira, espinhosa, giesta branca e amarela), tojos (arnal e molar), urzes (torga, roxa, peluda, branca e queiró), carqueja e tomilho-bravo, cujas utilizações são o pascigo de ovinos e caprinos, condimento aromatizante alimentar, medicinais, melíferas, lenhas, matéria-prima para estrume e ornamentais paisagísticas. Quanto à vegetação herbácea pratense, destacam-se as espécies - rabo-de-cão, festuca, feno-de-cheiro e trêvos (branco e roxo). Finalmente, a vegetação herbácea melífera, aromática e medicinal regista uma representação variada de hortelã-comum e poejo, dedaleira, 
milefólio ou erva-dos-carpinteiros, becabunga, erva-coelheira, cominho-dos-prados, sanabunda ou erva-benta e rabo-de-raposa (Franco, 1971 e 1984; Ribeiro, 1985; Ribeiro, 1987; Ribeiro et al., 1988; Sampaio, 1990; e Chinery et al., 1990).

\section{6 - Recursos Agro-Faunísticos Selvagens}

Continuando a análise na perspectiva agrária tradicional, os animais bravios (recursos agro-faunísticos selvagens) eram encarados no seu comportamento e utilidade, adaptados a cada espaço, participando no respectivo eco-sistema natural. Além da alimentação e outros usos comuns, proporcionavam ao homem recreio através das artes que tinha de utilizar para caçá-los ou pescá-los.

A fauna selvagem, destaca, nos mamíferos cinegéticos e predadores, o corço, javali, lebre-ibérica, coelho-bravo; e lobo, raposa e geneta. Entre as aves cinegéticas e predadoras, regista-se a rola-comum, perdiz-vermelha, codorniz, melro-comum, estorninhos, tordos (comum, ruívo e tordeia), narceja-galega e narceja-comum; e a águia-caçadeira, mocho-galego, corvo, águia-real, grifo, gralha-de-nuca-cinzenta, peneireiro-das-torres e mocho-d'orelhas. Nas espécies aquidulces piscatórias, o destaque cabe ao barbo-do-norte, escalo-do-norte, panjorca ou pardelha, verdemã-do-norte e truta-fário. Por último, a agro-fauna anfíbia e invertebrada regista as espécies comuns - rã, caracol-comum, abelha-doméstica e minhoca-terrestre (Félix et al, 1975; Costa et al, 1980; Rufino, 1989; Chinery et al, 1990; SNPRCN, 1990/1).

\section{3 - O MEIO AGRÁRIO HUMANIZADO TRANSMONTANO}

Este compreende as várias modalidades de estruturas agrárias, na perspectiva da integração agrária vertical (fileira), respectivamente, estruturas fundiárias e sociais, agro-produtoras, agro-transformadoras e agro-distribuidoras, mantendo como principal referência interpretativa a modernidade no equilibrio.

\section{1 - Estruturas Fundiárias e Sociais}

Inicia-se pela perspectiva institucional das estruturas agrárias quanto à relação terra - homem (estruturas fundiárias e sociais), expressas pelo regime fundiário de uso do solo, pela população agrária e pelas explorações agrárias, sobretudo, do sistema agrário camponês, registando o sistema agrário capitalizado uma expressão relativa. 


\subsection{1 - Regime de uso do solo}

Na perspectiva agrária tradicional, o regime de uso do solo é um misto de livre, imperativo e condicionado, uma vez que associa a iniciativa própria à imperatividade exigida pela subsistência do agregado familiar, condicionadora do uso mais adequado dos capitais fundiários terra e água à perpetuidade. No uso do solo, tratam-se as superficies de uso agrário, a agro-flora cultivada e a agro-fauna explorada RGA $^{10}$, 1989).

As superfícies de uso agrário são abordadas de forma mais abrangente do que o convencional. A superfície agrária útil (SAU) compreende o conjunto das superfícies cultivadas e das incultas passíveis de exploração, sendo obtida por subtracção da superficie territorial (ST) apenas da superfície social (SS), de uso não agrário. A superfície de uso agrícola (SUA) compreende os agrupamentos tradicionalmente considerados, à excepção das áreas de forragens e de pousio, de uso forrageiro-zootécnico, e das culturas permanentes com culturas sob-coberto não agrícolas, integradas na superfície de uso múltiplo agrário. A superfície de uso silvícola (SUS) corresponde à tradicional superficie de uso florestal subtraída das áreas de uso múltiplo do solo, em que a floresta anda associada a outros usos no respectivo sob-coberto. A superfície de uso múltiplo agrário (SUMA) agrega as componentes superficiais com vários usos simultâneos, com destaque para os incultos, acrescidos das áreas de culturas permanentes com culturas sob-coberto não agrícolas, áreas de floresta com culturas sob-coberto e outras áreas de uso social agrário, como eiras, logradouros, caminhos vicinais, etc.. Finalmente, a superfície de uso forrageiro-zootécnico (SUF/Z) integra as áreas forrageiras, prados e pastagens permanentes, pousios e culturas forrageiras anuais e temporárias, visando associar directamente os recursos forrageiros à sua utilização pecuária (Rosário, 1998).

A superficie agrária útil regista uma representação em que domina a superficie de uso silvícola e a superficie de uso agrícola, seguidas da superfície de uso forrageiro/zootécnico e da superfície de uso múltiplo agrário.

A agro-flora cultivada regista o domínio da área agrícola, em retracção, e da forrageira, apesar das potencialidades silvícolas. Nas culturas arvenses, domina o sistema anual milho-erva (azevém), milho-forragem estreme e batata, que nas áreas mais altas é batata-semente ${ }^{11}$, em rotação com prados anuais (azevéns) nos vales sub-montanos e nos planaltos regados, que na alta montanha dão lugar aos prados permanentes de regadio (lameiros húmidos) e nos planaltos aos cereais de sequeiro, pousio e prados permanentes de sequeiro (lameiros de secadal). A cobertura arvense de sequeiro e regadio regista uma 
proporção de 55-45\% (SROA, 1985). As arbustivo-arbóreas são dominadas pelos soutos nos andares sub-montano e montano, seguidos do pomar de frutos frescos de pomóideas e prunóideas e da vinha baixa em associação com o olival, que na zona atípica da Terra Quente é substituída pela associação do olival com o amendoal. Parte das áreas de montanha estão ocupadas por pinhal, de pinheiro-bravo e pinheiro-silvestre no Noroeste, e por carvalhal (negral e roble) e castinçal nos solos mais profundos, enquanto no Nordeste o pinheiro-bravo cede lugar ao carvalho-negral e à azinheira, e ao sobreiro na Terra Quente.

Quanto à agro-fauna explorada (autóctone e adaptada), o RGA, 1989 regista para Trás-os-Montes uma credível dominância de bovinos das raças autóctones de aptidão-carne, em sistema de semi-pastoreio, a raça mirandesa a nor-nordeste, a barrosã a nor-noroeste e a maronesa no centro-oeste transmontano. Os ovinos e caprinos autóctones das raças ovinas churra mirandesa, bragançana e indeterminada noroestina, enquanto os caprinos estão representados pela raça bravia na Montanha pastoril e pela serrana na pré-montanha. Os suínos e aves registam uma presença generalizada em exploração doméstica e alguma expressão em regime intensivo. A raça suína autóctone bísara, em vias de extinção, está a ser recuperada. As apícolas têm significado e um bom pascigo de flora melífera, assim como as cinegéticas em regime cinegético especial, através de reservas associativas, turísticas, municipais e sociais, que se propõem dar um contributo para a sustentabilidade agrária deste território, com vastas superfícies destinadas aos cereais sem produtividades competitivas. As espécies aquidulces, sobretudo a truta em regime livre, através do povoamento dos pequenos rios e barragens, e em regime controlado nos viveiros trutícolas. Entretanto, a referência simbólica aos animais de companhia regista a raça canina adaptada rafeiro-transmontano.

\subsection{2 - População Agrária}

A população agrária de Trás-os-Montes resultou do mestiçamento entre o povo primitivo - Ibero - e o Celta, que povoou este território no Século VI a.C., dando origem à cultura castreja. Estes povos tinham como modo de vida tradicional a agro-pastorícia de montanha, enquanto os vales férteis desbravados sob o domínio dos Romanos (Século III a.C.Século V) foram destinados à agricultura. As florestas dominavam as encostas. Com o cultivo dos vales sub-montanos, parte da população serrana instalou-se no sopé da montanha, fundando novas Aldeias em ligação directa com o vale e a montanha, segundo um modelar ordenamento agro-paisagístico. Com base nesta matriz sócio-cultural ancestral desenvolveu-se o quadro institucional agrário tradicional deste 
espaço (Caldas, 1978, 1991 e 1998). A população agrária regista baixa densidade, povoamento concentrado e feminização camponesa relativa, sendo a população agrária familiar dominante e a situação de pluri-actividade expressa no rendimento exterior superior para a origem agrária e serviços. Finalmente, a população agrária não familiar destaca a baixa representação de assalariados e patrões.

A população agrária familiar constitui o agrupamento mais numeroso, resultado da sua adequação à exploração do agros. $\mathrm{Na}$ população agrária familiar segundo a idade, destaca-se a inexistência dos estratos etários relativos aos jovens, enquanto os mais altos concentram mais de $50 \%$, traduzindo o elevado envelhecimento. Quanto à população agrária familiar, segundo a instrução, salientam-se as representações dos estratos Básico, $\mathrm{SLE}^{12}$ e $\mathrm{NSLNE}^{13}$, enquanto os estratos $\mathrm{SMP}^{14}$ e Superior registam valores insignificantes (RGA, 1989 e 1999). O produtor individual familiar segundo o tempo de actividade na exploração regista $<50 \%$ em regime de pluriactividade.

A população agrária não familiar, com representações baixas, destaca os assalariados permanentes, seguidos dos eventuais e valores baixos dos patronais.

$\mathrm{Na}$ última década, a estrutura social agrária continuou a degradar-se, concentrando-se em dois estratos etários - cerca de 50\% com idade activa efectiva e outros $50 \%$ com idade de reforma, face ao regime antecipado no âmbito da PAC.

\subsection{3 - Explorações Agrárias}

Referidos o uso do solo e a população agrária, seguem-se as entidades suas integradoras: as explorações agrárias, cujos vectores de análise a ter em conta são, respectivamente, número, área, parcelamento, natureza jurídica, formas de exploração e orientação técnico-económica (RGA, 1989).

Nas explorações agrárias destaca-se um número mais significativo para as agrícolas, seguidas das silvícolas, forrageiras e agrárias múltiplas. A dimensão física e o parcelamento crescem de oeste para leste, registando valores médios entre 4-8 ha e 7-12 blocos. O regime jurídico destaca o domínio da área de exploração autónoma com mais de metade da representação. As formas de exploração concentram o número na conta-própria com área superior à média, enquanto na renda fixa e variável o valor é baixo para o número e médio para a área. Finalmente, sob o ponto de vista da orientação técnico-económica, destacam-se as actividades centeio e batata, milho-forragem, milho-grão; pastagens de sequeiro, lameiros húmidos e de secadal; pomares de pomóideas, prunóideas, souto, vinha, e olival e amendoal (Terra Quente); bovinos e 
ovinos de carne e caprinos de leite-carne; castinçal, pinhal (orla noroestina), carvalhal e sobreiral.

\section{2 - Estruturas Agro-Produtoras}

Seguem-se as estruturas agro-produtoras segundo a estrutura produtiva, equipamento agrário e produtividade agrária, e atributos área média e efectivo médio (RGA, 1989).

A estrutura produtiva destaca, para as áreas médias, valores de cerca de 1ha para as agrícolas, de 2-3 ha nas silvícolas, de 2,5 ha nas agrárias múltiplas e de 2 ha nas forrageiras. Os efectivos animais revelam, igualmente, uma estrutura muito débil, com os bovinos concentrados nos escalões 1 e 2 animais por exploração (50\%), os ovinos nos 1, 2 e 3-4 (54\%), os suínos nos 1 e $2(80 \%)$ e as avícolas no 1-9 $(80 \%)$.

Quanto ao equipamento agrário consideram-se as empresas agro-produtoras segundo as benfeitorias e as máquinas e alfaias. Para as agro-produtoras segundo as benfeitorias, destaca-se a representação das explorações com rega e regadio colectivo e individual; com origem da água em nascentes, cursos de água natural e charcas; com rega por gravidade. As instalações estão de acordo com a estrutura dos efectivos animais. Quanto às agro-produtoras com máquinas e alfaias, destaca-se maior representação das explorações com tractores e alfaias nos escalões $<34 \mathrm{cv}$ e $34-<55 \mathrm{cv}$ e nas gadanheiras.

Finalmente, os indicadores agro-produtivos compreendem os índices de análise produtiva superfície/efectivo, produção e produtividade. A superfície das actividades agrícolas destaca o centeio e milho ${ }^{15}$, batata, pomares, soutos e vinha; nas silvícolas dominam o pinheiro-bravo e os carvalhos; nas agrárias múltiplas, os incultos; nas forrageiras, os cereais forrageiros (milho e centeio) ${ }^{15}$, os prados permanentes de regadio e sequeiro; e nos efectivos pecuários, os bovinos de carne, os ovinos e caprinos de carne-leite, seguidos dos suínos e aves.

$\mathrm{Na}$ produção, destacam-se as mesmas actividades agrícolas temporárias e permanentes, embora com ordem distinta, respectivamente, batata, fruta, castanha, centeio, vinho; enquanto na silvícola dominam o pinheiro-bravo; na forrageira, os cereais forrageiros e as consociações anuais; enquanto na pecuária, os bovinos de carne, seguidos de ovinos e caprinos, dos suínos e das aves.

Finalmente, a produtividade destaca a batata, o milho-grão e o centeio com $1 / 3$ do valor comunitário, enquanto a castanha, os frutos frescos e a uva registam mais de metade do valor comunitário. $\mathrm{Na}$ silvícola, é superior no pinheiro-bravo, carvalho e castanho. $\mathrm{Na}$ forrageira, destacam-se o milho-silagem e as consociações; enquanto a 
pecuária destaca os bovinos de carne, os suínos e as aves, com valores mais próximos dos comunitários (RGA, 1989; EA ${ }^{16}$, 1990; Eurostat, 1992). Contudo, há que atender a que o padrão comunitário então vigente era super-intensivo!

\section{3 - Estruturas Agro-Transformadoras}

Nas estruturas agro-transformadoras, destacam-se as principais características das agro-transformadoras alimentares e complementares. $\left(\mathrm{IT}^{17}, 1989\right.$; EA, 1990).

\subsection{1 - Agro-Transformadoras Alimentares}

Nas agro-transformadoras alimentares destacam-se a transformação de cereais, com pequenas unidades tradicionais e uma ou outra média unidade de moagem de ramas e rações e estrutura idêntica de unidades de panificação, mas mais generalizadas. $O$ fabrico de vinho regista, para o vinho de Trás-os-Montes de qualidade, $12 \%$ do total do vinho do Norte de Portugal, cuja laboração está cada vez mais concentrada em adegas cooperativas, por encerramento das pequenas adegas tradicionais e em adegas de "quinta", no sentido da qualidade do vinho. A extracção de azeite, por influência da zona atípica da Terra Quente, apresenta uma estrutura razoavelmente concentrada em lagares cooperativos de média-grande dimensão, por desistência dos pequenos lagares tradicionais, cuja falta de mecanização os inviabiliza do ponto de vista económico, à excepção daqueles que optam pela extracção de azeite ecológico, cuja valorização do produto the confere viabilidade. A transformação de frutos e hortícolas destaca alguns fruteiros frigoríficos de pequena e média dimensão e poucos de média/grande dimensão de carácter cooperativo. A transformação de carnes regista uma tradição artesanal significativa, em franco declínio com o êxodo agrário, mas que entrou numa fase de recuperação através de produtos com denominação de origem protegida; verifica-se a existência de algumas pequenas unidades de fabrico intensivo e poucas médias. A transformação de leite regista raras unidades médias de leite de vaca e algumas pequenas de fabrico de queijo de ovelha e de cabra, algumas com denominação de origem protegida.

\subsection{2 - Agro-Transformadoras Complementares}

Quanto às agro-transformadoras complementares, salienta-se a transformação de madeiras através da serração, da carpintaria, da tanoaria e da marcenaria, em pequenas e médias unidades de fabrico. A 
transformação agro-têxtil regista as actividades artesanais de fiação $e$ tecelagem de lã grosseira (burel) e de fiação e tecelagem de linho tradicional, mas com pequena expressão.

\section{4 - Estruturas Agro-Distribuidoras}

Relativamente às estruturas agro-distribuidoras, destacam-se os atributos de distribuição - proporção de explorações vendedoras, percentagem de vendas, forma de escoamento, local de venda $\mathrm{e}$ condições de venda, para as explorações agrícolas, pecuárias, silvícolas e agro-naturais (RGA, 1989).

\subsection{1 - Explorações agrícolas segundo os atributos de distribuição}

As explorações agrícolas segundo os atributos de distribuição destacam, para a batata, elevado valor de explorações vendedoras, com média percentagem de vendas, por venda directa, na exploração e mercados e feiras, a preço de momento. O milho-grão, destaca uma baixa proporção de explorações vendedoras e de percentagem de vendas, com domínio da venda directa, na exploração e a preço de momento. Os frutos frescos e secos destacam representações com elevada proporção de explorações vendedoras e percentagem de vendas, na exploração, através de intermediário e a preço de momento. A uva/vinho regista valor significativo do auto-abastecimento, venda directa e por adegas cooperativas, respectivamente, a preço de momento e posterior; enquanto para o vinho, as explorações vendedoras são relativamente poucas e pequena percentagem de vendas, por venda directa, na exploração e a preço livre. A azeitona para azeite regista uma percentagem de explorações vendedoras baixa e uma percentagem de vendas alta, o escoamento é através de cooperativas e intermediários, na exploração e a preço postecipado e livre; o azeite apresenta maior proporção de explorações vendedoras e de percentagem de vendas, o escoamento pela venda directa, na exploração e a preço livre.

\subsection{2 - Explorações pecuárias segundo os atributos de distribuição}

Quanto às explorações pecuárias segundo os atributos de distribuição, há a considerar os produtos pecuários animais e de origem animal. A distribuição dos produtos pecuários animais destaca, para os bovinos, uma elevada proporção de explorações vendedoras, com escoamento maioritário através de intermediários e venda directa, na exploração e mercados e feiras, a preço de momento, situação extensiva aos ovinos e caprinos. Os suínos e aves acusam valores baixos de 
explorações vendedoras, mas algumas intensivas, e uma percentagem de vendas intermédia, através de venda directa, na exploração e a preço de momento.

Entretanto, na distribuição de produtos pecuários de origem animal, destaca-se o leite de vaca com maior proporção de explorações vendedoras, com elevada percentagem de vendas, escoamento variado, através de empresas privadas lácteas e cooperativa, a preço de momento, antecipado e postecipado. Com representação significativa, o queijo de ovelha e de cabra apresenta poucas explorações vendedoras, elevada percentagem de vendas, por venda directa, na exploração e a preço de momento. Os ovos registam pequena expressão, com baixa proporção de explorações vendedoras, raras intensivas, escoamento maioritário por venda directa, na exploração e a preço de momento. Por último, o mel tem certo significado, em termos de explorações vendedoras e percentagem de vendas, com escoamento por venda directa, na exploração e a preço de momento.

\subsection{3 - Explorações silvícolas segundo os atributos de distribuição}

Entretanto, as explorações silvícolas segundo os atributos de distribuição não são abordadas por falta de dados estatísticos, sendo, contudo, do conhecimento geral que os produtos silvícolas têm uma distribuição discrepante do ponto de vista agrário, expressando a falta do elemento empresário no circuito, com as trocas a processarem-se, em regra, entre proprietário e comprador, agente (madeireiro, resineiro e corticeiro) que, em regra, procede à colheita dos produtos na árvore ou a própria árvore.

\subsection{4 - Explorações agro-naturais segundo os atributos de distribuição}

Por último, as explorações agro-naturais segundo os atributos de distribuição, quer em termos de produtos como de serviços, não são tratadas, igualmente, por falta de dados estatísticos, nomeadamente, para os produtos cinegéticos e da pesca aquidulce, as plantas aromáticas, melíferas e medicinais, e os serviços de recreio agro-paisagístico e actividades agro-artesanais. 
4 - A MODERNIZAÇÃO DO SISTEMA AGRÁRIO TRANSMONTANO E A SUSTENTABILIDADE

A análise da modernização sustentável do sistema agrário transmontano assenta na diversificação das várias funções do agros, segundo a óptica da multifuncionalidade agrária $\left(\operatorname{GREP}^{18}, 1999\right)$. Este sistema agrário é diversificado em actividades e deve apelar à sinergia resultante da assunção das várias funções agrárias, respectivamente, ambiental, económica e social.

\section{1 - Função Ambiental}

A função ambiental assenta na lógica das práticas agrárias tradicionais, embora com adaptações ao progresso técnico, no âmbito da produção integrada, em que a perspectiva da modernidade no equilíbrio se traduz no apelo ao retorno a rotações adequadas, à benfeitorização agrária ajustada, à fertilização orgânica como suporte da mineral, às mobilizações adequadas, ao maneio das actividades com apoio da mecanização, à protecção integrada e à colheita mecanizada. As rotações adequadas devem ser conformes aos solos e agro-sistemas por forma a proteger e melhorar o fundo de fertilidade e a proporcionar as melhores produtividades, devendo ser repensadas as técnicas modernas convencionais produtivistas em que os adubos químicos minerais e os pesticidas são os instrumentos de eleição. A benfeitorização agrária apela para a defesa dos solos contra a erosão, desde logo pela sua armação segundo as curvas de nível, mas também com recurso às culturas permanentes; apela, igualmente, à drenagem de áreas excessivamente húmidas que não seja aconselhável manter como eco-sistemas húmidos, caso dos lameiros húmidos. Por outro lado, no sentido de proporcionar a rega a áreas e a culturas cada vez mais diversificadas e significativas, apela-se ao recurso aos aproveitamentos hidráulicos; é necessário reforçar a maior parte dos regadios tradicionais e submeter à rega as várzeas da Terra Quente para a horto-fruticultura e de parte das peneplanícies de amendoal e olival de azeitona para conserva. A fertilização orgânica deve ser utilizada de forma sistemática nas várias modalidades conhecidas, como suporte da mineral, no sentido da manutenção do bom nível do fundo de fertilidade, da adequada estrutura e microbiologia do solo, devendo ser repensadas as técnicas modernas convencionais produtivistas em que os adubos químicos minerais são o instrumento de eleição. As mobilizações adequadas devem ser as ajustadas aos fins a que se destinam, não esquecendo uma boa estruturação e microbiologia do solo. Mais uma vez se considera oportuno recomendar que as técnicas modernas convencionais produtivistas, em que os herbicidas são 
instrumentos de eleição por substituição das lavouras, sejam repensadas, pois, além do combate às ervas daninhas, as mobilizações têm funções na estruturação e microbiologia do solo. O maneio das actividades deve apoiar-se numa adequada mecanização, mas sem atentar contra a natural etologia de plantas e animais, nestes em termos do seu bem-estar. A intensificação da produção deve estar contida nos limites do ecológico e etologicamente razoável, além da ética, por razões da elaboração adequada dos produtos, tendo em vista os aspectos nutricionais e de segurança alimentar. A protecção integrada deve ser estimulada, na linha do que está em curso, mas não só para algumas culturas, antes deve ser generalizada às culturas e povoamentos florestais e à pecuária. A colheita mecanizada deve ter em consideração as épocas mais ajustadas a uma boa qualidade dos produtos, circunstância directamente associada à mecanização desta operação. De tal modo que as dificuldades de mecanização constituem as maiores limitações à sustentabilidade de algumas actividades, caso da olivicultura.

Como atitude crítica face aos resultados do desrespeito da modernização convencional pela função ambiental agrária, a reforma da Política Agrária Comum (PAC) estabeleceu as medidas agro-ambientais, com vista a recuperar muitas situações de degradação agro-ambiental e a prevenir outras. Contudo, na perspectiva da modernidade no equilíbrio, alerta-se para a necessidade de ponderação das situações por forma a evitar que, num caso ou outro, em nome da conservação dos eco-agrosistemas, se tentem manter situações insustentáveis, quando o caminho da sustentabilidade era a reconversão das actividades.

\section{2 - Função Económica}

A função económica compreende os processos de integração agrária, respectivamente, de produção, de transformação e de distribuição de bens e serviços agrários. A produção agrária, pela sua ligação aos recursos agro-naturais, está muito associada à função ambiental, pelas externalidades que gera, umas positivas e outras negativas. Aliás, é oportuno repensar muitas das práticas produtivistas da modernização convencional, para reduzir as negativas ao mínimo, como é natural das práticas agrárias tradicionais. Por outro lado, a produção agrária constitui o processo básico da integração. Entretanto, a transformação agrária também tem implicações de ordem ambiental através das externalidades negativas que provoca em termos de resíduos, o processo agrário tradicionalmente maior contribuinte neste domínio. No entanto, salvaguardada a redução e eliminação dos impactos negativos destas externalidades, pela prevenção e o combate, a transformação desempenha um papel fundamental na sustentabilidade das actividades agrárias. Ao 
processar os produtos e, por esta forma, acrescentar-lhes valor, proporciona aos agrários o acesso a estas mais valias, que representam um rendimento agrário acrescido, o qual fertiliza as economias locais. Finalmente, a distribuição agrária, com implicações mais escassas no ambiente, presta igualmente um grande contributo à sustentabilidade das actividades agrárias, ao constituir outro processo do complexo agrário acrescentador de valor aos produtos por troca dos serviços prestados, em reforço dos rendimentos agrários, igualmente em benefício das economias locais.

Assim, através da integração, as actividades agrárias ganham viabilidade económica, isto é, sustentabilidade do ponto de vista da função económica.

\section{3 - Função Social}

A função social está relacionada com o emprego, a qualidade de vida e o bem-estar. A integração agrária responde às preocupações do emprego, na medida em que ao associar os processos produtivo, transformador e distribuidor está a assegurar a localização destas actividades, ao invés da sua deslocalização por venda da matéria-prima para transformação e distribuição noutros locais com todo o emprego que lhe está associado. Quanto à qualidade de vida, no que depende do acréscimo de rendimento, a integração proporciona aos agrários o acesso aos valores acrescentados da transformação e distribuição, porventura a única via natural de obtenção de rendimentos equivalentes aos das outras actividades económicas, da indústria e dos serviços, sem ser pela via duvidosa dos subsídios. Por outro lado, o controlo de qualidade e a segurança alimentar apelam para uma mais alargada certificação de produtos, garantia da opção de qualidade, que em sistemas pouco produtivos como o transmontano deve constituir a principal alternativa. Relativamente ao bem-estar, muito associado ao acréscimo de rendimentos, é também assegurado por uma integração agrária bem conseguida, que assegure muitas das garantias de escoamento dos produtos. Contudo com base na plena assunção da função ambiental agrária. 


\section{NOTAS}

* Esta comunicação foi apresentada no I Congresso de Estudos Rurais Território, Sociedade e Política - Continuidades e Rupturas, Área Temática: Território, Agricultura e Desenvolvimento, Universidade de Trás-os-Montes e Alto Douro, 16-18 de Setembro de 2001.

${ }^{1}$ A expressão modernidade no equilíbrio parece contraditória, na medida em que o progresso subjacente à modernidade implica sempre um certo desequilíbrio, constituindo a permanente tentativa de o compensar o seu principal estímulo... Em termos dos eco-sistemas agro-naturais, é conhecida a situação de fraca produtividade energética quando, por várias sucessões ecológicas, os respectivos elementos atingem a maturidade, situação que o homem permanentemente interrompe com a criação dos agro-sistemas humanizados, na via da acumulação ou reprodução energética (Barros, 1981)...... numa perspectiva de equilíbrio dinâmico permanente.

${ }^{2} \mathrm{O}$ agros, entendido como sinónimo de sector agrário, compreende as várias componentes sub-sectoriais integradas, desde as agro-naturais às agrário humanizadas, representadas as primeiras pelos recursos agro-naturais e as segundas pelas estruturas agrárias (Rosário, 1998).

${ }^{3}$ Espaço - área geográfica causa de múltiplas relações, onde se articulam aspectos da natureza e formas de vida humana específicas (Ribeiro, 1987).

${ }^{4}$ Região Natural - espaço harmónico dotado de personalidade, que lhe provém de um longo ajustamento de gerações ao ambiente que elas, em grande parte, modelaram (Ribeiro, 1987).

${ }^{5}$ Zona Homogénea - Sub-Região Natural, Comarca (Espanha), Pays (França): divisão traçada pela diferenciação sobretudo climática, exprime a relação espacial de factos complexos, físicos, biológicos e sócio-económicos que nelas se articulam (Ribeiro, 1987).

${ }^{6}$ Coeficiente de correcção geográfica criado para o efeito.

${ }^{7}$ Coeficiente de correcção ecológica criado para o efeito.

${ }^{8}$ SROA - Serviço de Reconhecimento e Ordenamento Agrário.

${ }^{9}$ Espécie naturalizada pelo homem, tornou-se subespontânea.

${ }^{10}$ RGA - Recenseamento Geral Agrícola.

${ }^{11}$ A cultura da batata-semente tem um grave problema de sustentabilidade, face à forte infestação dos solos com um vírus da batateira, devido à super-utilização do solo com a cultura e por não serem seguidas sistemáticamente as práticas de rotação alargada com prados temporários para interromper o ciclo do vírus, como há décadas está proposto.

${ }^{12}$ SLE - sabendo lêr e escrever.

${ }^{13} \mathrm{NSLNE}$ - não sabendo lêr nem escrever.

${ }^{14} \mathrm{SMP}$ - ensino secundário, médio e profissional.

${ }^{15}$ Estas actividades foram consideradas apenas em 50\% da superfície agrícola, tendo a outra parte sido atribuída às actividades forrageiras.

${ }^{16}$ EA - Estatísticas Agrícolas.

${ }^{17}$ IT - Indústrias Transformadoras.

${ }^{18}$ GREPPEA - Groupe de Recherche pour l'Education et la Prospective-Produire, Entretenir et Accueillir. 


\section{BIBLIOGRAFIA}

ALBUQUERQUE, J. Pina Manique (1984), Carta Ecológica (fito-edafo-climática), (III.4), Portugal. Atlas do Ambiente, Lisboa

ALBUQUERQUE, J. Pina Manique (1985), Carta das Regiões Naturais (caracterização eco-fisionómica), (III.5), Portugal. Atlas do Ambiente, Instituto Hidrográfico, Lisboa.

BARROS, Henrique de (1981), Economia e Ecologia, Livros Horizonte, Lisboa.

CALDAS, E. Castro (1978), A Agricultura Portuguesa no Limiar da Reforma Agrária, Centro de Estudo de Economia Agrária, Instituto Gulbenkian da Ciência, Fundação Caloust Gulbenkian, Lisboa.

CAlDAS, E. Castro (1991), A Agricultura Portuguesa Através dos Tempos, INIC, Lisboa.

CALDAS, E. Castro (1998), A Agricultura na História de Portugal, Ed. Empresa de Publicações Nacionais, Lda, Lisboa.

CARDOSO, J. Carvalho; BESSA, M. Teixeira; e MARADO, M. Branco (1978), Carta dos Solos (III.1), Comissão Nacional do Ambiente, Instituto Hidrográfico, Lisboa.

Carta dos Solos e Cartas do Uso Actual e Aptidão da Terra do Nordeste de Portugal (1991), Agroconsultores e Coba, UTAD/PDRITM, Vila Real.

CHINERY, Michael et al (1990), História Natural de Portugal e da Europa, Ed. Verbo, Lisboa.

COMISSÃO NACIONAL DO AMBIENTE (1982), Carta Hipsométrica (I.15), Portugal. Atlas do Ambiente, Instituto Hidrográfico, Lisboa.

COMISSÃO NACIONAL DO AMBIENTE (1987), Carta de Declives (I.14), Portugal. Atlas do Ambiente, Instituto Hidrográfico, Lisboa.

COSTA, C.E. et al. (1980), A Caça em Portugal (Vol. I e II, $2^{a}$ edição), Editorial Estampa, Lisboa.

DIVISÃO DE ESTATÍSTICAS INDUSTRIAIS (1989), Indústrias Transformadoras Anuais, Instituto Nacional de Estatística, Lisboa.

DIVISÃO DO ATLAS DO AMBIENTE (1989), Carta da Hidrografia Continental: Principais Bacias Hidrográficas (I.17), Portugal. Atlas do Ambiente, Direcção Geral dos Recursos Naturais, Instituto Hidrográfico, Lisboa.

EUROSTAT (1992), Estatísticas de Base da Comunidade, Serviço das Publicações Oficiais das Comunidades Europeias, Luxemburgo.

FÉLIX, J. et TRÍSKA, J. (1975), Faune et Flore d'Europe, Gründ, Paris.

FRANCO, J.A. (1971), Nova Flora de Portugal (Continente e Açores) (Vol. I), Lisboa.

FRANCO, J.A. (1984), Nova Flora de Portugal (Continente e Açores) (Vol. II), Lisboa.

Groupe de Recherche pour l'Education et la Prospective-Produire, Entretenir et Accueillir (1999), La Multifonctionnalité de l'Agriculture et le Contract Territorial d'Exploitation, POUR, no 164, Décembre.

INE (1989), Recenseamento Geral Agrícola do Continente, Instituto Nacional de Estatística, Lisboa.

INE (1990), Estatísticas Agricolas, Instituto Nacional de Estatística, Lisboa.

PEREIRA, J. Lima (1993), Aspectos Ecológico-Agrários da Produção Animal em Trás-os-Montes, Estudos Transmontanos ( $\mathrm{N}^{\mathrm{0}}$ 5), Vila Real.

QUINTELA, A. Carvalho (1975), Carta do Escoamento (quantidade de água na rede hidrográfica) (I.8), Direcção Geral dos Recursos Florestais/Instituto 
Hidrográfico, Comissão Nacional do Ambiente, Lisboa.

RIBEIRO, J. Alves (1985), Contribuição para o Estudo da Fitogeografia de Trás-osMontes e Alto Douro, UTAD, Vila Real.

RIBEIRO, O. (1987), Portugal. O Mediterrâneo e o Atlântico, $5^{\mathrm{a}}$ Edição, Colecção Nova Universidade, Livraria Sá da Costa Editora, Lisboa.

RIBEIRO, O.; LAUTENSACH, H.; DAVEAU, S. (1988), Geografia de Portugal (II Vol.) - O Ritmo Climático e a Paisagem, Edições João Sá da Costa, Lisboa.

ROSÁRIO, Manuel F. Colaço do (1998), Ensaio de Caracterização Agrária Integrada do Norte de Portugal no Contexto do Continente, Universidade de Trás-os-Montes e Alto Douro, Vila Real.

RUFINO, R. (1989), Atlas das Aves que Nidificam em Portugal Continental, Centro de Estudos de Migrações e Protecção de Aves, Secretaria de Estado do Ambiente e dos Recursos Naturais, Lisboa.

SAMPAIO, Gonçalo (1990), Flora Portuguesa, 4 ${ }^{\text {a }}$ Ed., Instituto Nacional de Investigação Nacional, Imprensa Nacional, Lisboa.

SERVIÇO DE RECONHECIMENTO E DE ORDENAMENTO AGRÁRIO (1982), Carta de Capacidade de Uso do Solo, (III.3), Portugal. Atlas do Ambiente, Instituto Hidrográfico, Lisboa).

SERVIÇO DE RECONHECIMENTO E DE ORDENAMENTO AGRÁRIO (1985), Carta da Distribuição de Culturas Arvenses de Sequeiro, (II.15), Portugal. Atlas do Ambiente, Instituto Hidrográfico, Lisboa.

SERVIÇO NACIONAL DE PARQUES, RESERVAS E CONSERVAÇÃO DA NATUREZA (1990), Livro Vermelho dos Vertebrados de Portugal (Vol. I) (Mamiferos, Aves, Répteis e Anfibios), Serviço Nacional de Parques, Reservas e Conservação da Natureza, Lisboa.

SERVIÇO NACIONAL DE PARQUES, RESERVAS E CONSERVAÇÃO DA NATUREZA (1991), Livro Vermelho dos Vertebrados de Portugal (Vol. II) (Peixes Dulciaquícolas e Migradores), Serviço Nacional de Parques, Reservas e Conservação da Natureza, Lisboa. 